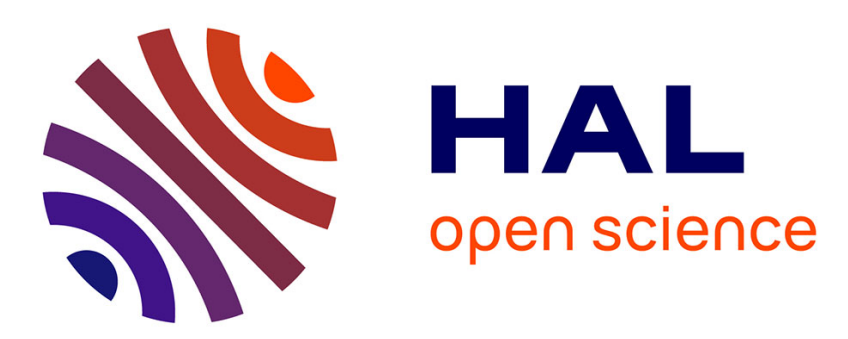

\title{
Detection of the alternative lengthening of telomeres pathway in malignant gliomas for improved molecular diagnosis
}

\author{
Anne Fogli, Marie-Véronique Demattei, Laetitia Corset, Catherine \\ Vaurs-Barrière, E. Chautard, Julian Biau, Jean-Louis Kemeny, Catherine \\ Godfraind, Bruno Pereira, Toufik Khalil, et al.
}

\section{To cite this version:}

Anne Fogli, Marie-Véronique Demattei, Laetitia Corset, Catherine Vaurs-Barrière, E. Chautard, et al.. Detection of the alternative lengthening of telomeres pathway in malignant gliomas for improved molecular diagnosis. Journal of Neuro-Oncology, 2017, 135 (2), pp.381-390. 10.1007/s11060-0172585-7 . hal-01643036

\section{HAL Id: hal-01643036 \\ https://hal.science/hal-01643036}

Submitted on 21 Nov 2017

HAL is a multi-disciplinary open access archive for the deposit and dissemination of scientific research documents, whether they are published or not. The documents may come from teaching and research institutions in France or abroad, or from public or private research centers.
L'archive ouverte pluridisciplinaire HAL, est destinée au dépôt et à la diffusion de documents scientifiques de niveau recherche, publiés ou non, émanant des établissements d'enseignement et de recherche français ou étrangers, des laboratoires publics ou privés. 


\section{Detection of the alternative lengthening of telomeres pathway in malignant gliomas for improved molecular diagnosis}

Anne Fogli ${ }^{1,2,3,4}$, Marie-Véronique Demattei ${ }^{5}$, Laetitia Corset $^{5}$, Catherine Vaurs-Barrière ${ }^{1,2,3}$, Emmanuel Chautard $^{6,7}$, Julian Biau ${ }^{6,7}$, Jean-Louis Kémény ${ }^{6,8}$, Catherine Godfraind ${ }^{8,9}$, Bruno Pereira ${ }^{10}$, Toufik Khali1 ${ }^{11,12}$, Nathalie Grandin ${ }^{5}$, Philippe Arnaud ${ }^{1,2,3}$, Michel Charbonneau ${ }^{5^{*}}$ and Pierre Verrelle ${ }^{6,13^{*}}$

${ }^{1}$ French National Institute for Health and Medical Research (INSERM), UMR1103, 63001 Clermont-Ferrand, France

${ }^{2}$ French National Center on Scientific Research (CNRS), UMR6293, 63001 Clermont-Ferrand, France

${ }^{3}$ Clermont Université, Université d'Auvergne, Laboratoire GReD, BP 10448, 63000 Clermont-Ferrand, France

${ }^{4}$ Biochemistry and Molecular Biology Department, Clermont-Ferrand Hospital, Clermont-Ferrand, 63003, France

${ }^{5}$ UMR CNRS 7292, Université François-Rabelais de Tours, 37200 Tours, France

${ }^{6}$ Clermont Université, Université d'Auvergne, EA 7283, CREaT, BP 10448, 63000 Clermont-Ferrand, France

${ }^{7}$ Centre Jean Perrin, Département de Radiothérapie, Laboratoire de Radio-Oncologie Expérimentale 63000 Clermont-Ferrand, France

${ }^{8}$ CHU Clermont-Ferrand, Service d'Anatomopathologie, 63003 Clermont-Ferrand, France

9 Clermont Université, Université d'Auvergne, EA4677, ERTICa, 28 Place Henri Dunant, 63000 ClermontFerrand, France

${ }^{10}$ CHU Clermont-Ferrand, Biostatistics unit, DRCI, 63003 Clermont-Ferrand, France

${ }^{11}$ CHU Clermont-Ferrand, Service de Neurochirurgie, 63003 Clermont-Ferrand, France

${ }^{12}$ Clermont Université, Université d'Auvergne, EA 7282, IGCNC, BP 10448, 63000 Clermont-Ferrand, France

${ }^{13}$ Institut Curie, Département de Radiothérapie, Paris, France

* Co-senior authors

Running title: Molecular telomeric markers in gliomas

Total manuscript word count: 3,980 (text w/o abstract, w/o references)

\section{Corresponding author:}

Michel CHARBONNEAU

e-mail: michel.charbonneau@uca.fr

Phone number: (33) 247366084

Fax number: (33) 473276132 


\begin{abstract}
Human malignant gliomas exhibit acquisition of either one of two telomere maintenance mechanisms, resulting from either reactivation of telomerase expression or activation of an alternative lengthening of telomeres (ALT) mechanism. In the present study, we analyzed 63 human malignant gliomas for the presence of ALT-specific extrachromosomal circles of telomeric DNA (C-circles) and measured telomerase expression, telomeric DNA content (Telo/Alu method), and telomeric repeat-containing RNAs (TERRA) levels. We also assessed histomolecular markers routinely used in clinical practice. The presence of C-circles significantly correlated with IDH1/2 mutation, MGMT exon 1 methylation, low Ki-67 immunostaining, increased telomeric DNA content, absence of functional ATRX protein and level of HTERT gene expression. In multivariate analysis, we observed a trend to a correlation between elevated TERRA levels and increased survival. Interestingly, the C-circles assay allowed to detect ALT activation in glioblastomas exhibiting wild-type IDH1/2 and ATRX expression. These results suggest that, after the correlations uncovered here have been confirmed on larger numbers of tumors, telomeric markers might be useful in improving diagnosis. They also point out to the utility of using the specific, sensitive and quantitative C-circle and Telo/Alu assays that can work with as few as 30 ng of tumor DNA.
\end{abstract}

Keywords: gliomas; telomeric markers; alternative lengthening of telomeres; C-circle assay; ATRX expression. 


\section{Introduction}

Telomeres, which represent the ends of linear chromosomes of eukaryotic organisms and contain repeated noncoding TG-rich sequences, protect chromosome ends from DNA repair activities occurring following DNA damage. By limiting the replicative potential of cells, telomere length serves as a "mitotic clock" and telomere erosion acts as a barrier against tumorigenesis in healthy tissue [1]. Following cancer initiation, tumor cells must overcome the telomere-controlled replicative senescence barrier to be able to proliferate indefinitely. In most cases (around $90 \%$ of cancer types) this occurs through up-regulation of telomerase expression. However, some cancer cells maintain their telomeres through a telomerase-independent process termed ALT, for "Alternative Lengthening of Telomeres" [2]. ALT is thought to function principally by exchange of telomeric sequences from one telomere to the next (recombination). There is also good evidence that a sort of "rolling circle" mechanism could also lead to telomere amplification on a single telomere [3, 4]. Human gliomas are among the $\sim 10 \%$ of cancer types that can survive either owing to telomerase or the ALT pathway [5]. Clinical studies indicate that 15 to $45 \%$ of human malignant gliomas develop the ALT pathway and that this is strongly associated with the low grade II which can exhibit up to $75 \%$ of ALT $[6,7]$.

Recent clinical studies have highlighted the existence of a strong correlation between the occurrence of the ALT pathway of telomere maintenance in several types of ALT cancers and the presence of mutations in the

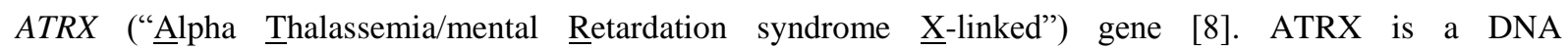
helicase/ATPase of the SWI2/SNF2 family that binds repeated sequences of DNA, particularly the G-rich ones, and has been implicated mainly in chromatin remodeling [9].

C-circles are single- and double-stranded extrachromosomal DNA circles that, unlike other categories of extrachromosomal DNA species, are specific for the ALT pathway [10]. Potentially, C-circles represent the product of excision of over-elongated telomeres that have been previously amplified by homologous recombination between repeated telomeric sequences during ALT [3]. In the present study, we assessed for the presence of the ALT pathway, using the very sensitive and quantifiable C-circle assay, and other telomere markers in 63 grades II, III and IV gliomas. We next attempted to correlate these factors with clinical characteristics as well as with the occurrence of classical genetic/epigenetic markers.

\section{Materials and methods}

\section{Ethics statement}


Between 2007 and 2012, malignant glioma samples were obtained during therapeutic surgical management by the Neurosurgery Unit of Clermont-Ferrand hospital (France) and stored confidentially. These glioma samples were part of the "Tumorothèque Auvergne Gliomes" biobank (DC-2012-1584). This study obtained ethical approval from the ethics committees and the respective competent authorities. The authors state that they have complied with the World Medical Association Declaration of Helsinki regarding ethical conduct of research involving human subjects.

\section{Patients and tissue collection}

The clinical samples used in this study were taken from the material resected during the course of a standard diagnostic and treatment procedure. Immediately after surgery, the samples were snap-frozen and stored in liquid nitrogen.

Each sample was analyzed under a light microscope after hematoxylin-eosin staining for assessing necrosis and tumor cell percentage. Samples with less than $50 \%$ of tumor cells were excluded from this study. Histological diagnosis and grading of gliomas were based on WHO criteria used at the time of sample analyses of the present study [11]. Four non-tumoral control brain samples (healthy controls, mean age of 27.3, standard deviation \pm 2 years) were cadaveric specimens removed by autopsy 4-16 hr following accidental death (Brain and Tissue Bank of Maryland). These four non-tumoral control samples, identified by the Brain and Tissue Bank of Maryland as corpus callosus $(n=1)$ and frontal cortex $(n=3)$, corresponded to white matter enriched in astrocytes and oligodendrocytes, tissue from which gliomas originate. Tumor and control samples were processed by cryogenic grinding used for homogenization in powder and equally distributed into at least three vials, as described previously [12]. For each sample, two vials were used for DNA and RNA extractions.

Survival was calculated from the date of surgery. The extent of tumor resection was evaluated essentially based on two criteria: the surgical procedure report by the neurosurgeon and the presence of a persistent contrast-enhancement on the early post-surgery (48 h) CT scan or MRI. The degree of tumor resection was classified as: i) gross total resection (GTR) when tumor surgery was optimal and no contrast enhancement detected at 24/48 h post-surgery MRI, or ii) as partial resection (PR) when contrast enhancement was detected.

\section{DNA sequencing for $I D H 1 / 2$ mutational analysis and methylation status of $M G M T$ promoter}


Genomic DNA was isolated from frozen tissues using the QIAamp DNA Mini Kit (Qiagen) and stored at $-80^{\circ} \mathrm{C}$. $I D H 1$ and $I D H 2$ genotyping and MGMT promoter methylation analyses were performed as previously described [12-14] and detailed in Supplementary methods.

\section{Analysis of 1p/19q codeletion, INA and immunostaining}

The analysis of $1 \mathrm{p} / 19 \mathrm{q}$ codeletion, internexin neuronal intermediate filament protein alpha (INA) expression [15, 16] and immunostaining analyses were detailed in Supplementary methods.

\section{Measurements of ALT-specific C-circles}

The C-circle assay, which detects partially single-stranded telomeric (CCCTAA)n DNA circles (C-circles) amplified by the Phi29 polymerase in the absence of dCTP, was performed as described previously [10] and detailed in Supplementary methods.

Detection of ALT-associated promyelocytic leukemia nuclear bodies (APBs) at the telomeres APBs detection was conducted according to protocols previously described [5, 17] and detailed in Supplementary methods.

\section{Telomeric DNA quantification by dot blot}

Ten nanogramms of genomic DNA were transferred to a nylon membrane (Hybond N+; GE Healthcare) in a dot blot apparatus (Bio-Rad). After high-stringency washes, the membrane was hybridized overnight, in Church buffer, with a ${ }^{32} \mathrm{P}$-labeled telomeric repeat $[\mathrm{TTAGGG}]_{3}$ probe that had been end-labeled with $100 \mu \mathrm{Ci}{ }^{32} \mathrm{P}-\gamma \mathrm{ATP}$ at $37^{\circ} \mathrm{C}$ for $40 \mathrm{~min}$ using $\mathrm{T} 4$ polynucleotide kinase. After detection, the membrane was stripped and re-probed with an Alu-specific [GTGATCCGCCCGCCTCGGCCTCCCAAAGTG] ${ }^{32}$ P-labeled probe, as above.

\section{Measurement of $h T E R T$ expression}

Total RNA was isolated from tumors using RNeasy Mini Kits (Qiagen). A reverse transcription reaction was performed on 500 ng RNA using the High Capacity cDNA Reverse Transcription kit (Applied Biosystems) according to manufacturer's instructions. hTERT expression was measured using the nanofluidic digital PCR array platform (Fluidigm technology). The expression level of $h T E R T$ for each sample was calculated compared 
to the three housekeeping genes $T B P, R P L 13 A$ and PPIA, identified as valid control genes in human glioma [18] and using the $\Delta \Delta \mathrm{Ct}$ method [19].

\section{Measurement of telomeric DNA transcription (TERRA)}

Two micrograms of tumor sample RNA were reverse transcribed using the Revertaid first strand cDNA synthesis kit from Thermo Scientific-Fermentas and quantified using specific primers as previously described [20] and detailed in Supplementary methods.

\section{Cell lines and cell culturing}

Cell lines and culturing are described in Supplementary methods.

\section{Telomere length measurement of human cancer cell lines by telomere restriction fragment (TRF) analysis} Measurement of telomere length was performed by Southern blot analysis, also referred to as TRF (Telomere Restriction Fragment) analysis as already described [21, 22] and detailed in Supplementary methods.

\section{Statistical analysis}

Statistical analysis was performed using the Stata software, version 12 (StataCorp, College Station, TX, USA). Tests were two-sided, with a type I error set at $\alpha=0.05$. Baseline characteristics were presented as mean \pm standard deviation (sd) or as median [interquartile range] for each independent group for continuous data and as number of patients and associated percentages for categorical parameters. Comparisons of characteristics between groups were analyzed using Chi-squared or Fisher's exact test for categorical variables, and Student's ttest or Mann-Whitney test for quantitative variables when assumptions of t-test were not met ((i) normality verified by the Shapiro-Wilk test and (ii) homoscedasticity by the Fisher-Snedecor test). Correlation between quantitative parameters was accessed using correlation coefficient noted $\mathrm{r}$ (Pearson or Spearman according to statistical distribution). Multivariate analysis was considered to take into account adjustment on possible confusing factors according to univariate analysis and literature: age, WHO grade, surgery resection. Overall survival (OS) was defined as the interval from surgery to death, regardless of the cause of death. OS curves and estimates were constructed using the Kaplan-Meier method. The log-rank test was used in a univariate analysis to test the prognostic value of patient characteristics. Cox proportional hazards regression was used to investigate prognostic factors in multivariate situation by backward and forward stepwise analysis of the factors 
considered significant in univariate analysis (entered into the model if $\mathrm{p} \leq 0.15$ ) and according to clinically relevant parameters. The proportional hazard hypotheses were verified using Schoenfeld's test and plotting residuals. The interactions between possible predictive factors were also tested. Results were expressed as hazard ratios (HR) and $95 \%$ confidence intervals $(\mathrm{CI})$.

\section{Results}

A total of 63 malignant glioma samples were analyzed; patient characterisitics are outlined in Supplementary

Table 1. According to the previous WHO glioma classification [11], this cohort comprised 23 GBM (mean age of $63.0 \pm 9.5$ years), 32 grade III (mean age of $57.4 \pm 12.6$ years) and 8 grade II (mean age of $40.1 \pm 10.0$ years). However, importantly, the definition of glioma sub-classes for our statistical analyses was based on criteria similar to those used in the new WHO classification [23], meaning that, for instance, grades II and III were grouped together but further classified according to their IDH1/2 and 1p/19q codeletion status. All patients underwent surgery. High-grade (III and IV) IDH WT glioma patients were treated by concurrent chemoradiation and adjuvant chemotherapy (temozolomide), while IDH -mutated glioma patients did not receive concurrent chemoradiation and were treated on a case-by-case basis with protocols selected by our neuro oncology staff (chemotherapy and/or radiation, not simultaneously).

\section{Occurrence of the ALT mechanism of telomere maintenance}

All 63 glioma samples were analyzed for the presence of ALT-specific C-circles (Figure 1A, Supplementary

Table 1). We chose the so-called "C-circle assay" to measure ALT activity, a technique developped by Reddel and co-workers, because it is highly specific, highly sensitive and quantifiable and can work with as little as 30 ng of DNA [10]. The intensities of C-circle signal for cells from a telomerase positive cancer cell line, HeLa, as well as for a prototype of ALT positive cells, U2OS, an osteosarcoma-derived cell line, were measured under identical conditions. Two out of the 9 C-circle positive tumors had a higher signal than U2OS, both of which were IDH1/2 WT GBM (Supplementary Table 1). Since the C-circle method for identification of the ALT mechanism is recent, we set out to detect in parallel, on a subset of samples, the presence of ALT-associated promyelocytic leukemia nuclear bodies (APBs) (Figure 1B). In the C-circle positive tumors, co-localizing signals were detected in the microscope (Figure 1B), but not in the ALT negative tumors (data not shown).

Nine out of the 63 samples analyzed (14.2\%) were positive in the C-circle assay. The IDH1/2 mutated and IDHI/2 WT groups exhibited a statistically significant difference, with only 3 C-circle positive tumors 
among the 49 IDH WT gliomas ( $p=0.001$; Table 1). Six out of the $9(66.7 \%)$ C-circle positive tumors versus only $8 / 54(14.8 \%)$ C-circle negative tumors were IDH-mutated, pointing out to a statistically significant association between $I D H 1 / 2$ mutations and ALT ( $\mathrm{p}=0.001$, Table 1). In addition, C-circle positive patients were diagnosed at a younger age than $\mathrm{C}$-circle negative patients ( $\mathrm{p}=0.04$, Table 2 ).

Median survival was statistically different between the patients negative (15.8 months) and positive (41.9 months) for $\mathrm{C}$-circle, when considering the entire population ( $\mathrm{p}=0.03, \mathrm{HR}=0.28,95 \%$ CI $[0.09 ; 0.90])$. In addition, 5-year survival was $22 \%$ in $\mathrm{C}$-circle negative versus $62 \%$ in C-circle positive tumors. Moreover, even if one of the $6 \mathrm{C}$-circle positive living patients died, the difference would remain statistically significant. When using multivariate model adjusted on the diagnosis age, histopathology grading and surgery resection, there was a trend for a significantly different OS depending on C-circle status ( $\mathrm{p}=0.09, \mathrm{HR}=0.35,95 \%$ CI $[0.10 ; 1.17]$. Therefore, C-circle status did not appear to be an independent prognostic factor in our series of 63 gliomas.

Thirty four/63 tumors (54\%) exhibited methylation of MGMT exon 1. MGMT promoter methylation correlated not only with the occurrence of $I D H 1 / 2$ mutations $(\mathrm{p}=0.001)$ but also with the presence of $\mathrm{C}$-circles $(\mathrm{p}=0.02$; Table 1). This relation was less robust when considering the IDH mutated and IDH WT groups separately, but a trend was observed in the IDH WT group (39.1\% versus $100 \%, \mathrm{p}=0.07)$. Therefore, $M G M T$ methylation correlates with the presence of the ALT mechanism.

\section{hTERT expression}

The expression of $h T E R T$, encoding the catalytic subunit of telomerase, exhibited a mean increase of 9.3-fold in the 43 tumors tested in comparison to four control brain samples (Table 1). Although hTERT expression was different between IDH mutated and IDH WT gliomas (5.0 \pm 6.1 and $10.1 \pm 7.6$ respectively), this difference was not statistically significant ( $\mathrm{p}=0.12$, Table 2 ), most likely due to the small number of IDH mutated samples $(\mathrm{n}=14)$

Overall survival was inversely correlated with hTERT expression in univariate (HR=1.08, [1.03 - 1.14], $\mathrm{p}=0.001)$ and multivariate $(\mathrm{HR}=1.08,[1.03-1.13], \mathrm{p}=0.003)$ analyses. This correlation becomes more significant in the $1 \mathrm{p} / 19 \mathrm{q}$ negative group $(37 / 53 ; \mathrm{HR}=1.09,[1.03-1.15], \mathrm{p}=0.001)$, as expected from previous results [24], and even in the IDH WT group (36/49; HR=1.09, [1.03 - 1.15] $\mathrm{p}=0.002)$. Therefore, hTERT expression was an independent negative prognostic factor in the whole population. All 5 C-circle positive gliomas in which it was measured exhibited a very low, undetectable, rate of hTERT expression, whereas expression was higher in C-circle negative gliomas $(10.5 \pm 7.2, n=38, \mathrm{p}<0.001$; Table 1), highlighting the 
existence of a moderate inverse correlation between hTERT expression and the ALT mechanism ( $\mathrm{r}=0.31$, $\mathrm{p}=0.04)$.

\section{Telomeric DNA content and telomeric DNA transcripts (TERRA)}

In the current study, we had approximately $100 \mathrm{ng}$ of tumor DNA available for each sample and this was not enough if we wanted to measure telomere length using telomere restriction fragment (TRF) analysis. To increase the sensitivity, we quantified telomeric DNA (TTAGGG repeats) with respect to an internal control (amount of Alu repeats), referred to as the Telo/Alu dot blot method (see Materials and methods), which we performed here using 10 ng of tumor DNA per sample (Figure 2A; Supplementary Table 1; Supplementary results). Using six different human cell lines, we confirm that the Telo/Alu dot blot signals were proportional to telomere length measured by TRF (Figure 2B and Supplementary results), and can be useful to approximate absolute values of telomere length, in kilobases.

No statistically significant difference in telomeric DNA content nor in TERRA expression [25, 26] was found in relation with $I D H 1 / 2$ mutational status (Table 2). On the other hand, a significant positive association was found between long telomeres and the presence of $\mathrm{C}$-circles $(\mathrm{p}=0.03,0.7$ [0.54 - 0.87] versus 0.83 [0.70 1], Table 1). For instance, tumor \#30 exhibited a 42.18 C-circle score and a 1.77 Telo/Alu ratio, the highest among all tumors measured (Supplementary Table 1). Finally, statistical analyses showed no correlation between telomeric DNA content/telomere length and survival $(\mathrm{HR}=1.16,[0.41-3.31], \mathrm{p}=0.78)$.

\section{Analysis of classical molecular markers in a context other than telomeric}

\section{IDH1/2 mutation status}

Within the IDH WT group ( $\mathrm{n}=49)$, overall survival was similar between GBM $(n=23)$ and grade III gliomas $(\mathrm{n}=25), 1.03$ and 1.32 year, respectively. Median survival between IDH WT $(n=49)$ and mutated $(n=14)$ populations was significantly different $(\mathrm{p}=0.001)$ with respectively 14.4 months [8.5 - 24.3] (5-year survival: 9\%) for IDH WT and not reached at the moment for IDH mutated (5-year survival: $86 \%$ ).

\section{ATRX inactivation}

In ALT positive tumors, inactivation of the ATRX gene product by mutation, insertion or deletion causes a lack of nuclear expression detected by immunolabeling, while tumors without ALT show robust nuclear labeling for ATRX [27, 28]. An absence of ATRX protein expression was found in 5/59 tested gliomas. This absence of 
functional nuclear ATRX was linked to activation of the ALT pathway ( $\mathrm{p}=0.001$, Table 1), but also to the presence of an IDH1/2 mutation ( $\mathrm{p}<0.001$, Table 2), but not to $M G M T$ promoter methylation $(\mathrm{p}=0.15)$. Interestingly, ATRX was nuclear (and therefore presumably functional) in all 3 C-circle positive GBMs.

\section{MGMT exon 1 methylation status}

Thirty-four (54\%) tumors had their MGMT promoter methylated (Supplementary Table 1). There was a strong correlation $(\mathrm{p}=0.001)$ between methylation and the occurrence of an IDHI/2 mutation, since 13/14 (92.9\%) IDH1/2 mutated tumors (tumor \#52 being the exception) exhibited MGMT methylation, while only $42.9 \%$ of IDH1/2 WT tumors were MGMT-methylated. There was also a strong relation between overall survival and MGMT methylation with a univariate approach $(\mathrm{HR}=0.28,[0.15-0.53], \mathrm{p}<0.001)$, but also after adjustment using a multivariate model $(\mathrm{HR}=0.31,[0.16-0.61], \mathrm{p}=0.001)$.

\section{$1 p / 19 q$ codeletion}

All tumors were assessed for the presence of either $1 \mathrm{p} / 19 \mathrm{q}$ codeletion $(\mathrm{n}=38)$ or INA immunostaining $(\mathrm{n}=25)$. Among the 10 positive tumors, 9 were $I D H$-mutated $(\mathrm{p}<0.001)$. In fact, patient $\# 71$ diagnosed as $1 \mathrm{p} / 19 \mathrm{q}$ codeleted based on INA expression, turned out to be negative for $1 \mathrm{p} / 19 \mathrm{q}$ codeletion following subsequent CNV analysis, which detected only partial codeletions on $1 \mathrm{p}$ and $19 \mathrm{q}$ chromosome arms (see Supplementary methods). MGMT promoter methylation in these $10 \mathrm{1p} / 19 \mathrm{q}$ codeleted tumors was $36.8 \%$ versus $17.0 \%$ in the 53 non codeleted tumors (median: $37.7 \%$ [32.3 - 44.7] versus 5.9\% [1.7 - 29.5]), $\mathrm{p}=0.004$ ).

\section{P53 and Ki-67 immunostaining}

P53 immunoreactivity was not correlated with any parameter, while the proliferation marker Ki-67 was found to be an independent prognostic factor. Indeed, a low Ki-67 immunostaining was associated with better survival ( $\mathrm{p}<0.001)$. In addition, a low Ki-67 score is also associated with C-circle positivity ( $\mathrm{p}=0.02$, Table 1;

\section{Supplementary Table 1).}

\section{Discussion}

In the present study, we have measured, in a small cohort of human malignant gliomas, basic telomeric parameters and evaluated their potential association with classical tumor markers and clinical outcome. Some of our conclusions confirm previous studies [7, 29, 30], while others represent novel findings, which will have to be 
confirmed on a larger cohort. We have described a simple dot blot technique which, coupled with telomere length measurement in cell lines for calibration, allows to evaluate telomeric DNA content and telomere length in these tumors using as little as $30 \mathrm{ng}$ of DNA. In parallel, the already described C-circle technique, which accurately and specifically measures ALT activity, can also be used with similar low amounts of tumor DNA. There are currently three main methods for detecting ALT in tumors. The first one is TRF Southern-blot analysis of telomere length profile, also used here (Fig. 2). In ALT cells, telomeres range from very short to extremely long in individual cells, with mean telomere length $(>20 \mathrm{~Kb})$ being about twice of that of cells with positive telomerase activity or normal somatic cells $(5-10 \mathrm{~Kb})$. Therefore, ALT have long and heterogeneous telomeres as compared to the shorter and more homogeneous telomeres of ALT negative cells. TRF analysis currently uses around 3-5 $\mu \mathrm{g}$ of DNA per sample. The second method is that of the C-circles, used here, in which only $30 \mathrm{ng}$ of DNA are needed. The third method does not use tumor DNA as the starting material. It consists in the detection, in tumor sections, of ALT-associated PML bodies (APBs), which are promyelocytic leukemia (PML) bodies that contain telomeric DNA and telomere binding proteins. This method, also used here (Fig. 1B), is labor-intensive, making screening of large numbers of tumors difficult. However, recently, a variation of this assay, in which telomere FISH was used to detect ultra-bright telomeric signals, was used to analyze more than 6,000 tumor samples, mostly in tissue microarray format studies [31].

An interesting finding of the present study was that all 3 ALT positive tumors detected among the 23 GBM were wild type for $I D H 1 / 2$, while the remaining 6 ALT positive tumors detected among the 40 lower grades, were all mutated for IDH1/2. Importantly, GBM that were both C-circle/ALT positive and IDH1/2 WT did not exhibit loss of ATRX function, unlike ALT positive grade II and III gliomas which were all IDH1/2 mutated. This highlights the relevance to measure C-circles rather than ATRX protein expression to identify ALT positive tumors among IDH WT malignant gliomas. In addition, these observations lead to propose that ALT activity in GBM might not have the same causes and consquences as ALT activity in lower grades. Therefore, measuring ALT activity in all grades of gliomas will undoubtfully allow to distinguish sub-classes of gliomas. However, it should be stressed out again that larger numbers of analyzed cases will be needed in order to establish solid conclusions regarding the potential existence of two (or more) different sub-classes of ALT tumors.

Another new finding from the present study was that MGMT promoter methylation associated with the ALT pathway both in the IDH mutated and IDH WT groups. In fact, it has already been reported that MGMT promoter methylation associated with mutations in $I D H 1 / 2$ [32, 33] as well as with increased survival [33]. Our 
data also reveal, in multivariate analysis, a highly significant correlation between OS and a low Ki-67 score $(\mathrm{p}=0.004, \mathrm{HR}=1.05)$ as well as a trend to a correlation between $\mathrm{OS}$ and C-circle positivity $(\mathrm{p}=0.09, \mathrm{HR}=0.35)$. Our conclusion that a low Ki-67 score is associated with C-circle positivity should be toned down by the fact that the Ki-67 value was unknown for 5/9 C-circle positive tumors, and therefore is based on a small number of cases.

As expected, there was a strong inverse correlation between $h T E R T$ expression and the presence of a functional ALT mechanism. In addition, high levels of hTERT expression correlated with decreased survival, especially in $1 \mathrm{p} / 19 \mathrm{q}$ non-codeleted patients. This agrees with recent findings showing that the presence of mutations in the hTERT promoter of GBMs, associated with increased hTERT expression, correlated with decreased survival in $1 \mathrm{p} / 19 \mathrm{q}$ non-codeleted patients [24]. We found a positive correlation between telomeric DNA content and the presence of C-circles, which was expected since ALT telomeres are much longer in average than telomerase-maintained telomeres [3]. However, we believe it would be relevant to detect the presence of high versus low telomeric DNA content by using just a simple technique (the Telo/Alu method) since telomere length might represent a marker of tumor radiosensitivity [34]. On the other hand, we found no positive correlation between high telomeric DNA content and the presence of an IDHI/2 mutation. This was not surprising since a substantial number of tumors were IDH1/2 mutated but ALT negative.

In summary, achievement of a molecular diagnostic of ALT activation using the C-circle assay provides several major advantages. First, this assay specifically, accurately and rapidly identifies ALT positive tumors using as little as few tens of tumor DNA. This will be particularly useful for GBMs since those, contrary to low grade gliomas, can be wild type for both IDHI/2 and ATRX and yet develop the ALT pathway. Therefore, in these GBMs, routinely assessing IDHI/2 mutations by sequencing and $A T R X$ expression on tumor sections would not represent the right assay to detect ALT. Moreover, the C-circle assay reflects the overall ALT activity of the tumor, DNA being extracted from the whole chirurgical sample, contrary to the detection of ALTassociated PML bodies or FISH techniques, which both might accidentally analyze only a subset of tumor cells. In addition, FISH only indirectly assesses ALT activity, which is deduced from the signal measuring the amount of telomeric sequences, which might be misleading given that some tumors might exhibit long telomeres but yet be ALT negative. New ALT targeting therapies are currently under development [35] and it is therefore urgent to develop a reliable clinical test such as the C-circle assay to measure ALT activity in glioma tumors.

\section{Acknowledgments}


We thank Mélanie Müller-Barthélémy and Annette Quinsat for technical assistance, Valérie Gouilleux for the gift of cell lines, as well as the "Département Génomique PPF ASB” facility at University François-Rabelais of Tours for access to the Storm phosphorimager. This work was supported by grants from the "Fondation de France" and from the "Ligue Grand-Ouest contre le Cancer, comités Eure-et-Loir, Ille-et-Vilaine, Indre-et-Loire, Morbihan, Vendée, Vienne" (MC lab) as well as from The French National Research Agency (ANR: project BIVANDEV), the "Ligue contre le Cancer, comités du Puy-de-Dôme et Ardèche", the "Fondation ARC", and the "Conseil régional d'Auvergne" (PA lab), and the Plan Cancer-INSERM (CS14085CS “Gliobiv") (PV and PA labs).

\section{Conflicts of interest}

All authors declare that they have no conflict of interest.

\section{References}

1 Artandi SE, DePinho RA (2010). Telomeres and telomerase in cancer. Carcinogenesis 31:9-18.

2 Bryan TM, Englezou A, Dalla-Pozza L et al. (1997) Evidence for an alternative mechanism for maintaining telomere length in human tumors and tumor-derived cell lines. Nat Med 3:1271-4.

3 Pickett HA, Reddel RR (2015). Molecular mechanisms of activity and derepression of alternative lengthening of telomeres. Nat Struct Mol Biol 22:875-80.

4 Durant ST (2012). Telomerase-independent paths to immortality in predictable cancer sub-types. J Canc 3:6782.

5 Henson JD, Hannay JA, SmcCarthy SW et al. (2005). A robust assay for Alternative Lengthening of Telomeres in tumors shows the significance of Alternative Lengthening of Telomeres in sarcomas and astrocytomas. Clin Cancer Res 11:217-25.

6 Hakin-Smith V, Jellinek DA, Levy D et al (2003) Alternative lengthening of telomeres and survival in patients with glioblastoma multiforme. Lancet 361:836-8.

7 McDonald KL, McDonnell J, Muntoni A et al (2010). Presence of alternative lengthening of telomeres mechanism in patients with glioblastoma identifies a less aggressive tumor type with longer survival. J Neuropathol Exp Neurol 69:729-36.

8 Heaphy CM, de Wilde RF, Jiao Y et al (2011). Altered telomeres in tumors with ATRX and DAXX mutations. Science 1333: 425. 
9 Bérubé NG (2011). ATRX in chromatin assembly and genomearchitecture during development and disease. Biochem Cell Biol 89:435-44.

10 Henson JD, Cao Y, Huschtscha LI et al (2009). DNA C-circles are specific and quantifiable markers of alternative-lengthening-of-telomeres activity. Nat Biotechnol 27:1181-6.

11 Louis DN, Ohgaki H, Wiestler OD et al (2007). The 2007 WHO classification of tumours of the central nervous system. Acta Neuropathol 114:97-109.

12 Fogli A, Chautard E, Vaurs-Barrière C et al (2016). The tumoral A genotype of the MGMT rs34180180 single-nucleotide polymorphism in aggressive gliomas is associated with shorter patients' survival. Carcinogenesis 37:169-76.

13 Karayan-Tapon L, Quillien V, Guilhot J et al (2010). Prognostic value of O6-methylguanine-DNA methyltransferase status in glioblastoma patients, assessed by five different methods. J Neurooncol 97:311-22.

14 Quillien V, Lavenu A, Karayan-Tapon L et al (2012). Comparative assessment of 5 methods (methylationspecific polymerase chain reaction, MethyLight, pyrosequencing, methylation-sensitive high-resolution melting, and immunohistochemistry) to analyze O6-methylguanine-DNA-methyltranferase in a series of 100 glioblastoma patients. Cancer 118:4201-11.

15 Ducray F, Crinière E, Idbaih A et al (2009). Alpha-internexin expression identifies 1p19q codeleted gliomas. Neurology 72:156-61.

16 Ducray F, Mokhtari K, Crinière E et al (2011). Diagnostic and prognostic value of alpha internexin expression in a series of 409 gliomas. Eur J Cancer 47:802-8.

17 Yeager T, Neumann A, Englezou A et al (1999). Telomerase-negative immortalized human cells contain a novel type of promyelocytic leukemia (PML) body. Cancer Res 59: 4175-9.

18 Kreth S, Heyn J, Grau S et al (2010). Identification of valid endogenous control genes for determining gene expression in human glioma. Neuro-Oncol 12:570-9.

19 Livak KJ, Schmittgen TD (2001). Analysis of relative gene expression data using real-time quantitative PCR and the 2(-Delta Delta C(T)) method. Methods 25:402-8.

20 Sampl S, Pramhas S, Stern C et al (2012). Expression of telomeres in astrocytoma WHO grade 2 t0 4: TERRA level correlates with telomere length, telomerase activity, and advanced clinical grade. Transl Oncol 5:56-65.

21 Broccoli D, Godley LA, Donehower LA et al (1996). Telomerase activation in mouse mammary tumours: lack of telomere shortening and evidence for regulation of telomerase with RNA cell proliferation. Mol Cell Biol $16: 3765-72$. 
22 Aubert G, Hills M, Lansdorp PM (2012). Telomere length measurement - Caveats and a critical assessment of the available technologies and tools. Mut Res 730:59-67.

23 Louis DN, Perry A, Reifenberger G et al (2016). The 2016 World Health Organization classification of tumors of the central nervous system: a summary. Acta Neuropatol $131: 803-20$.

24 Killela PJ, Reitman ZJ, Jiao Y et al (2013). TERT promoter mutations occur frequently in gliomas and a subset of tumors derived from cells with low rates of self-renewal. Proc Natl Acad Sci USA 110:6021-6.

25 Azzalin CM, Reichenbach P, Khoriauli L et al (2007). Telomeric repeat containing RNA and RNA surveillance factors at mammalian chromosome ends. Science 318:798-801.

26 Azzalin CM, Lingner J (2014). Telomere functions grounding on TERRA firma. Trends Cell Biol 25:29-36.

27 Heaphy CM, de Wilde RF, Jiao Y et al (2011). Altered telomeres in tumors with ATRX and DAXX mutations. Science 333:425.

28 Bower K, Napier CE, Cole SL et al (2012). Loss of wild-type ATRX expression in somatic cell hybrids segregates with activation of alternative lengthening of telomeres. PLoS One 7:e50062.

29 Royds JA, Al Nadaf S, Wiles AK et al (2011). The CDKN2A G500 allele is more frequent in GBM patients with no defined telomere maintenance mechanism tumors and is associated with poorer survival. PLoS One 6:e26737.

30 Jiao Y, Killela PJ, Reitman ZJ et al (2012). Frequent ATRX, CIC, FUBP1 and IDH1 mutations refine the classification of malignant gliomas. Oncotarget 3:709-22.

31 Heaphy CM, Subhawong AP, Hong SM et al (2011). Prevalence of the alternative lengthening of telomeres telomere maintenance mechanism in human cancer subtypes. Am J Pathol 179:1608-15.

32 Yan W, Zhang W, You G et al (2012). Correlation of IDH1 mutation with clinicopathologic factors and prognosis in primary glioblastoma: A Report of 118 patients from China. PLoS One 7:e30339.

33 Leu S, von Felten S, Frank S et al (2013). IDH/MGMT-driven molecular classification of low-grade glioma is a strong predictor for long-term survival. Neuro-Oncol 15:469-79.

34 Ferrandon S, Saultier P, Carras J et al. (2013) Telomere profiling: toward glioblastoma personalized medicine. Mol Neurobiol 47:64-76.

35 Flynn RL, Cox KE, Jeitany M et al (2015) Alternative lengthening of telomeres renders cancer cells hypersensitive to ATR inhibitors. Science 347:273-7. 


\section{Legends of Figures}

Fig. 1. Detection of ALT-specific C-circle by C-circle assay and of ALT-specific APBs by immunofluorescenceFISH. (A) Dot blot of the C-circle assay using a ${ }^{32}$ P-labeled (TTAGGG) $)_{3}$ telomeric probe. All 64 samples were processed similarly, but a few examples only are shown here for illustration. Absolute C-circle values were measured by quantifying the signal after subtraction of the background signal on the nitrocellulose membrane. The vertical bars below represent the respective intensities of these values. The horizontal dashed line, which represents the C-circle value measured for HeLa cells (which are telomerase-positive), was arbitrarily chosen to establish a cut-off value below which tumors were considered ALT negative. Genomic DNA from an osteosarcoma-derived cell line, U2OS, a prototype of ALT positive cells, was used as a positive control for the C-circle reaction. (B) Detection of APBs by immunofluorescence using combined Telo-FISH analysis (red) and labeling with anti-PML antibodies (green). This is an example of a grade B oligodendroglioma (tumor \#76) that was found to be ALT positive using the C-circle assay, representative of four analyzed tumors that were C-circle positive, two primary GBM and two grade B oligodendrogliomas.

Fig. 2. Quantification of total telomeric DNA content in patient tumors by dot blot analysis using the so-called Telo/Alu method (see Materials and methods). (A) Hybridization of the indicated tumor DNAs (10 ng per sample) with a ${ }^{32} \mathrm{P}$-labeled (TTAGGG) 3 telomeric probe (top panel) or with a ${ }^{32} \mathrm{P}$-labeled Alu probe (bottom panel) that was used to normalize the telomeric signal to the total amount of genomic DNA. All 64 samples were processed similarly, but a few examples only are shown here for illustration. (B) Telomere length was measured in 6 cell lines using TRF analysis (30 $\mu \mathrm{g}$ per sample). Telomeric DNA content was measured in parallel in these 6 cell lines using the Telo/Alu method, as described above in A. This aimed at establishing a correlation between the total amount of telomeric DNA determined by the dot blot analysis and absolute telomere length measured in parallel using TRF analysis. A ${ }^{32}$ P-labeled (TTAGGG) 3 telomeric probe was used for both types of measurements. Horizontal dotted lines within the gel represent the upper and lower limits of each smear of telomeric tracts. The center of this smear is usually used to assess a telomeric mean value in kilobases of DNA. Note that the length of the smear is also important because it reflects the degree of scattering of all telomeres lengths around the mean value of the whole cell population. 
Table 1: Statistical comparative analyses depending on C-circle status

\begin{tabular}{|c|c|c|c|c|c|}
\hline & Total & $\begin{array}{r}\text { Patients } \\
\text { negative for } \\
\text { C-circles } \\
(n=54) \\
\end{array}$ & $\begin{array}{r}\text { Patients } \\
\text { positive for } \\
\text { C-circles } \\
(n=9) \\
\end{array}$ & $\mathbf{p}^{(\mathbf{a})}$ & $\mathbf{p}^{(\mathbf{b})}$ \\
\hline Gender: male, $\mathrm{n}$ & $38 / 63(60.3 \%)$ & $33 / 54(61.1 \%)$ & $5 / 9(55.6 \%)$ & 0.75 & NP \\
\hline Age, mean \pm sd & $57.1 \pm 13.1$ & $58.7 \pm 11.7$ & $47.6 \pm 17.7$ & 0.04 & NP \\
\hline IDH1/2 mutation & $14 / 63(22.2 \%)$ & $8 / 54(14.8 \%)$ & $6 / 9(66.7 \%)$ & 0.001 & NP \\
\hline $1 \mathrm{p} / 19 \mathrm{q}$ codeletion or mutated INA & $10 / 63(15.9 \%)$ & $9 / 54(16.7 \%)$ & $1 / 9(11.1 \%)$ & 1.00 & 0.99 \\
\hline Methylation MGMT>8\% & $34 / 63(54.0 \%)$ & $26 / 54(48.2 \%)$ & $8 / 9(88.9 \%)$ & 0.02 & 0.30 \\
\hline ATRX mutation & $5 / 59(8.5 \%)$ & $1 / 51(2.0 \%)$ & $4 / 8(50.0 \%)$ & 0.001 & 0.02 \\
\hline P53 mutation & $12 / 58(20.7 \%)$ & $8 / 49(16.3 \%)$ & $4 / 9(44.4 \%)$ & 0.08 & 0.14 \\
\hline $\begin{array}{l}\text { Telomeric DNA content (Telo/Alu } \\
\text { ratio), mean } \pm \mathrm{sd}^{(\mathrm{c})}\end{array}$ & $0.75 \pm 0.26$ & $0.73 \pm 0.22$ & $0.89 \pm 0.41$ & 0.24 & $\mathbf{0 . 0 3}$ \\
\hline hTERT, mean $\pm \mathrm{sd}^{(\mathrm{c})}$ & $9.3 \pm 7.5$ & $\begin{array}{r}10.5 \pm 7.2 \\
(\mathrm{n}=38)\end{array}$ & $\begin{array}{l}0 \pm 0 \\
(\mathrm{n}=5)\end{array}$ & $<0.001$ & 0.01 \\
\hline TERRA, mean $\pm \mathrm{sd}^{(\mathrm{c})}$ & $2.53 \pm 3.83$ & $\begin{array}{r}1.9 \pm 1.1 \\
(n=31)\end{array}$ & $\begin{array}{r}8.6 \pm 12.8 \\
(n=3)\end{array}$ & 0.88 & 0.69 \\
\hline $\mathrm{Ki}-67$, mean $\pm \mathrm{sd}^{(\mathrm{c})}$ & $32.3 \pm 14.8$ & $\begin{array}{r}34.2 \pm 14.0 \\
(\mathrm{n}=38)\end{array}$ & $\begin{array}{r}14.3 \pm 10.5 \\
(\mathrm{n}=4)\end{array}$ & 0.02 & 0.11 \\
\hline
\end{tabular}

${ }^{(a)}$ Univariate analysis

(b) Multivariate analysis adjusted on diagnosis age, histopathology grading, surgery type and IDH status

${ }^{(c)}$ Quantitative levels, as explained in the material and methods section

NP: not performed

Complete data were available for all parameters (63/63), except for P53 mutation (58/63), Ki-67

(42/63), ATRX (59/63), hTERT (43/63) and TERRA (34/63). 
Table 2: Telomeric markers according to IDH status

\begin{tabular}{|c|c|c|c|c|}
\hline & $\begin{array}{r}\text { Total } \\
(n=63)\end{array}$ & $\begin{array}{r}\text { IDH mut. } \\
(n=14)\end{array}$ & $\begin{array}{r}\text { IDH WT } \\
(\mathrm{n}=49)\end{array}$ & $\mathbf{p}$ \\
\hline $\begin{array}{l}\text { ATRX mutated/non mutated, } \mathrm{n} \\
(\%)\end{array}$ & $5 / 59(8.5)$ & $5 / 12(41.7)$ & $0 / 47(0.0)$ & $<0.001$ \\
\hline C-circle positive, n (\%) & $9(14.3)$ & $6(42.9)$ & $3(6.1)$ & 0.001 \\
\hline $\begin{array}{l}\text { Telomeric DNA content } \\
\text { (Telo/Alu ratio), mean } \pm \text { sd }\end{array}$ & $0.75 \pm 0.26$ & $0.70 \pm 0.25$ & $0.76 \pm 0.26$ & 0.46 \\
\hline hTERT expression, mean \pm sd & $9.3 \pm 7.5$ & $5.0 \pm 6.1$ & $10.1 \pm 7.6$ & 0.12 \\
\hline TERRA, mean \pm sd & $2.53 \pm 3.83$ & $5.29 \pm 8.88$ & $1.94 \pm 1.13$ & 0.68 \\
\hline
\end{tabular}

Complete data were available for all parameters (63/63), except for P53 mutation (58/63), Ki-67 (42/63), ATRX mutation (59/63), hTERT expression (43/63) and TERRA (34/63). 
Figure 1

A

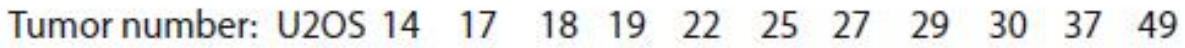
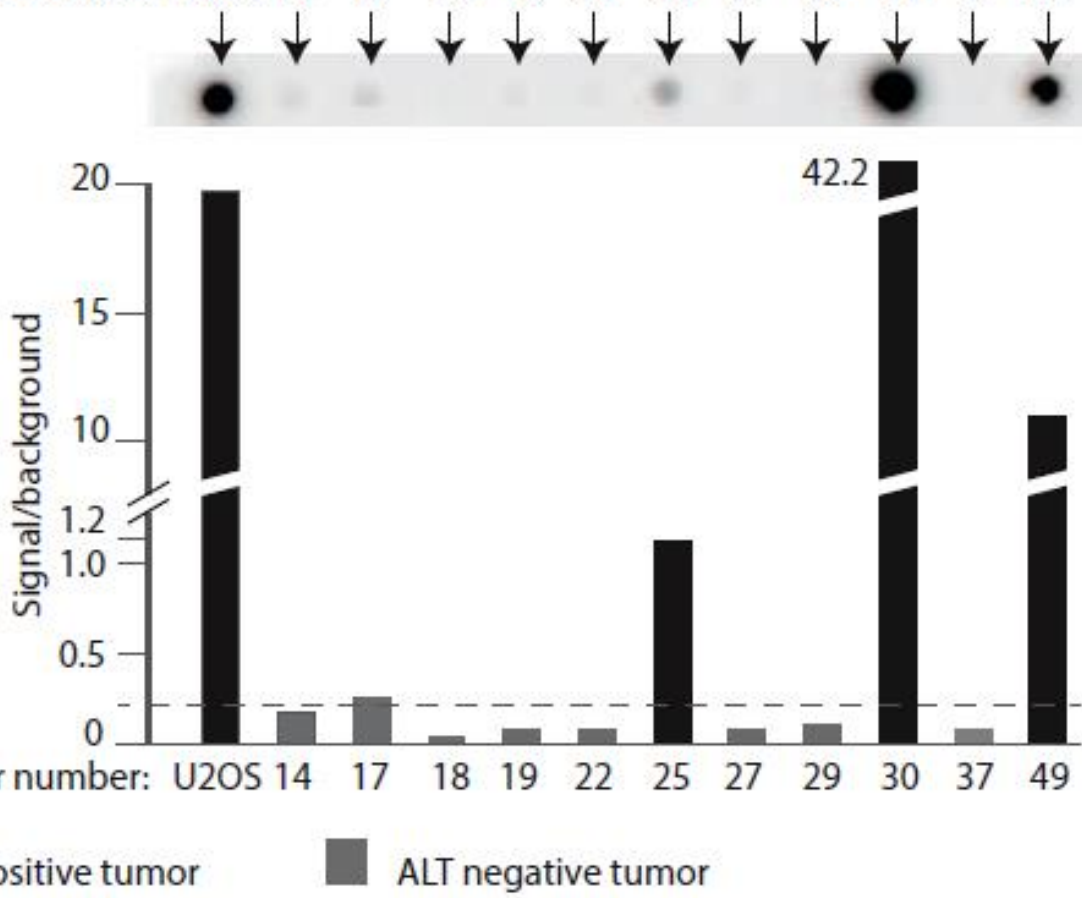

B
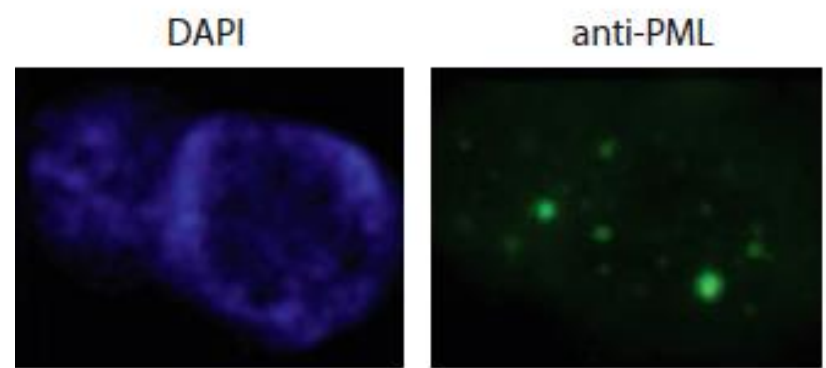

FISH (TTAGGG-PNA)

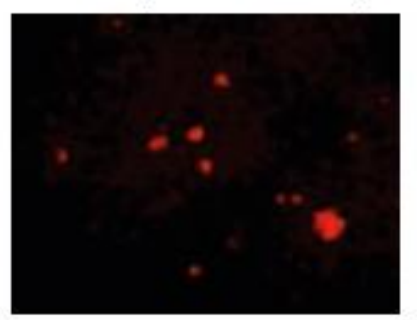

Merge
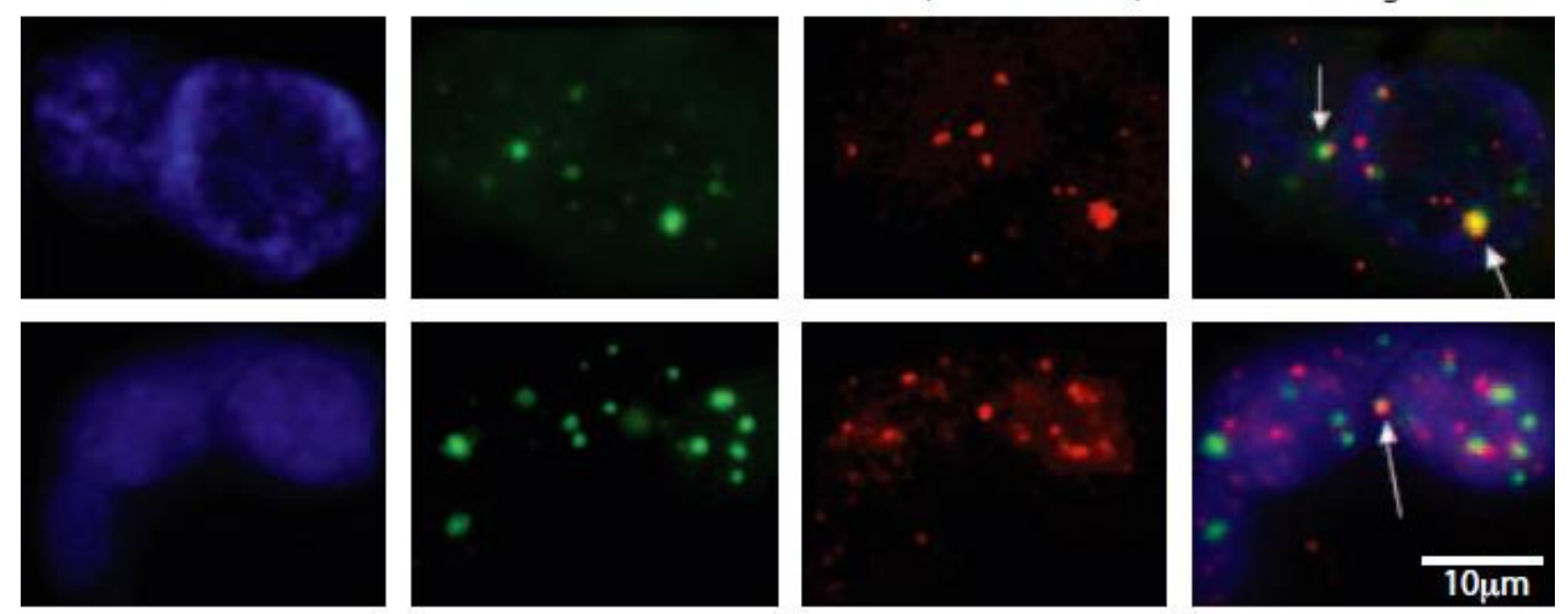
Figure 2

$\begin{array}{llllllllllll}\text { A } & \text { Tumor number: } & 29 & 36 & 39 & 44 & 59 & 70 & 78 & 80 & 83 & 84\end{array}$

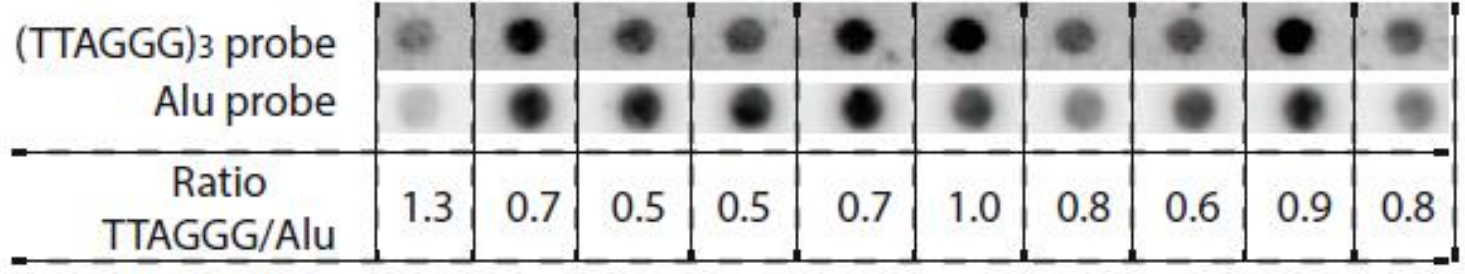

B
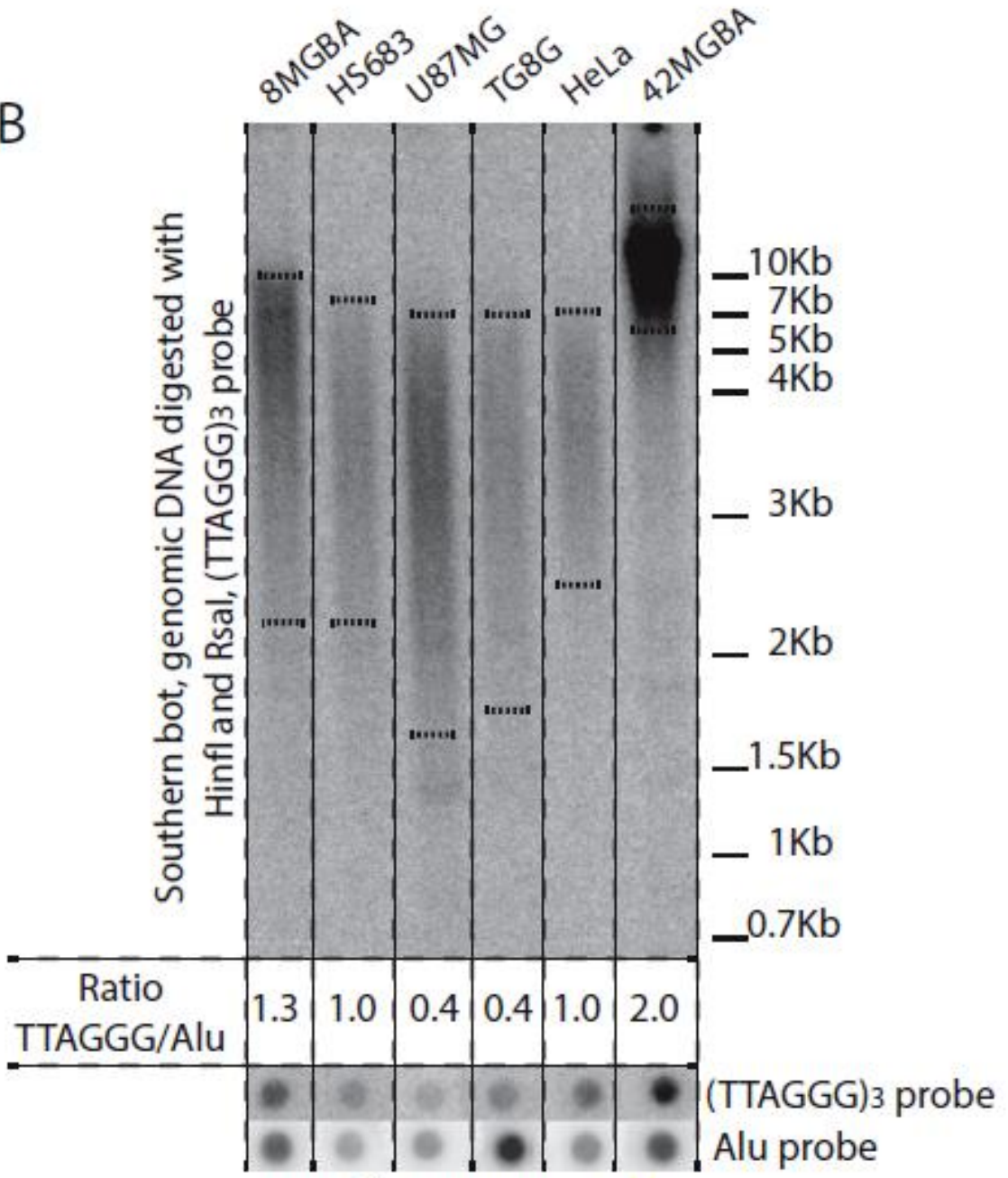

Dot blot, genomic DNA digested with Hinfl and Rsal 
Supplementary Table 1: Molecular analyses results

\begin{tabular}{|c|c|c|c|c|c|c|c|c|c|c|c|c|}
\hline $\begin{array}{c}\text { Case } \\
\text { number }\end{array}$ & $\begin{array}{l}\text { WHO } \\
\text { grades }\end{array}$ & $\begin{array}{l}1 \mathrm{p} / 19 \mathrm{q} \\
\text { codel. }^{\text {a }}\end{array}$ & IDH1 & IDH2 & $\begin{array}{l}\text { MGMT mean } \\
\text { methyl. }(\%) b\end{array}$ & C-circle & $\begin{array}{c}\text { C-circle } \\
\text { quantif. }\end{array}$ & $\begin{array}{l}\text { Telomere length } \\
\text { (Telo/Alu) }\end{array}$ & $\begin{array}{l}\text { hTERT } \\
\text { quantif. }\end{array}$ & TERRA quantif. & $\mathrm{p53}^{\mathrm{d}}$ & Ki-67 (\%) \\
\hline 6 & IV & 0 & WT & WT & 24.0 & + & 21.7 & 0.83 & $<0.01$ & NA & + & 30 \\
\hline 7 & IV & 0 & WT & WT & 18.7 & - & 0.16 & 0.72 & NA & $3.8 \pm 0.8$ & + & 40 \\
\hline 9 & IV & 0 & WT & WT & 1.1 & - & 0.06 & 0.62 & $20.3 \pm 3.1$ & $0.9 \pm 0.2$ & - & 40 \\
\hline 10 & IV & 0 & WT & WT & 2.2 & - & 0.09 & 0.92 & NA & NA & - & 30 \\
\hline 13 & IV & 0 & WT & WT & 1.2 & - & 0.02 & 0.54 & NA & NA & - & 30 \\
\hline 14 & IV & 0 & WT & WT & 1.1 & - & 0.18 & 0.69 & $10 \pm 2.8$ & NA & - & 40 \\
\hline 16 & IV & 0 & WT & WT & 46.9 & - & 0 & 0.51 & NA & NA & NA & NA \\
\hline 17 & IV & 0 & WT & WT & 49.2 & - & 0.27 & 1.12 & NA & NA & - & 30 \\
\hline 18 & IV & 0 & WT & WT & 1.3 & - & 0.05 & 0.5 & $3.4 \pm 1.6$ & NA & - & NA \\
\hline 19 & IV & 0 & WT & WT & 1.7 & - & 0.09 & 0.78 & $28.7 \pm 5$ & NA & + & NA \\
\hline 22 & IV & 0 & WT & WT & 13.2 & - & 0.09 & 0.72 & $5.3 \pm 2.9$ & NA & + & 20 \\
\hline 23 & IV & 0 & WT & WT & 1.3 & - & 0 & 0.75 & $6.1 \pm 0.2$ & $2.6 \pm 0.3$ & - & NA \\
\hline 25 & IV & 0 & WT & WT & 29.8 & + & 1.18 & 0.4 & NA & NA & + & NA \\
\hline 26 & IV & 0 & WT & WT & 19.5 & - & 0.02 & 0.82 & $4.7 \pm 0.1$ & $1.1 \pm 0.3$ & - & 40 \\
\hline 27 & IV & 0 & WT & WT & 2.1 & - & 0.08 & 0.92 & NA & NA & - & 35 \\
\hline 29 & IV & 0 & WT & WT & 0.8 & - & 0.12 & 1.31 & $0.3 \pm 0.1$ & $1.2 \pm 0.3$ & - & NA \\
\hline 30 & IV & 0 & WT & WT & 24.6 & + & 42.18 & 1.77 & $<0.01$ & NA & - & NA \\
\hline 32 & IV & 0 & WT & WT & 2.4 & - & 0.03 & 0.43 & $8.4 \pm 0.7$ & $0.5 \pm 0.1$ & - & 30 \\
\hline 34 & IV & 0 & WT & WT & 58.2 & - & 0.02 & 0.66 & $9.2 \pm 6$ & $0.7 \pm 0.1$ & - & 30 \\
\hline 36 & IV & 0 & WT & WT & 1.6 & - & 0.01 & 0.69 & $19.8 \pm 0.7$ & $1.7 \pm 0.2$ & NA & 30 \\
\hline 37 & IV & 0 & WT & WT & 1.5 & - & 0.08 & 0.34 & NA & NA & - & 50 \\
\hline 39 & IV & 0 & WT & WT & 53.9 & - & 0.02 & 0.52 & $11.8 \pm 3.4$ & $1.4 \pm 0.2$ & + & 70 \\
\hline 40 & IV & 0 & WT & WT & 1.3 & - & 0 & 0.53 & NA & NA & - & 30 \\
\hline 41 & II & 0 & $\begin{array}{c}\text { WT } \\
\text { R132C }\end{array}$ & WT & 5.4 & - & 0.25 & 0.64 & $<0.01$ & NA & - & 5 \\
\hline 42 & III & 1 & het & WT & 31.8 & + & 0.74 & 0.49 & $<0.01$ & $1.3 \pm 0.2$ & + & NA \\
\hline
\end{tabular}




\begin{tabular}{|c|c|c|c|c|c|c|c|c|c|c|c|c|}
\hline 44 & III & 1 & $\begin{array}{l}\text { R132L } \\
\text { het } \\
\text { R132H }\end{array}$ & WT & 44.6 & - & 0.03 & 0.47 & $9.7 \pm 1.2$ & $1.2 \pm 0.3$ & - & 40 \\
\hline 45 & II & 1 & $\begin{array}{l}\text { het } \\
\text { R132H }\end{array}$ & WT & 22.5 & - & 0.07 & 0.65 & $1.5 \pm 0.2$ & NA & - & 30 \\
\hline 47 & II & 1 & het & WT & 29.2 & - & 0.08 & 0.55 & NA & NA & - & $<5$ \\
\hline 48 & III & 1 & $\begin{array}{c}\text { WT } \\
\text { R132H }\end{array}$ & $\begin{array}{l}\text { R172 } \\
\text { M het }\end{array}$ & 47.5 & - & 0.08 & 0.5 & NA & NA & NA & 40 \\
\hline 49 & II & 0 & $\begin{array}{c}\text { het } \\
\text { R132C }\end{array}$ & WT & 30.2 & + & 11.8 & 0.74 & $<0.01$ & $23.4 \pm 4.4$ & - & 8 \\
\hline 50 & II & 0 & $\begin{array}{c}\text { het } \\
\text { R132H }\end{array}$ & WT & 40.9 & + & 11.5 & 0.7 & NA & NA & - & NA \\
\hline 52 & II & 0 & $\begin{array}{c}\text { het } \\
\text { R132H }\end{array}$ & WT & 6.4 & + & 4.9 & 1 & NA & NA & - & 9 \\
\hline 53 & II & 1 & $\begin{array}{c}\text { het } \\
\text { R132H }\end{array}$ & WT & 36.7 & - & 0.09 & 0.51 & NA & NA & - & 3 \\
\hline 54 & II & 1 & $\begin{array}{c}\text { het } \\
\text { R132H }\end{array}$ & WT & 50.1 & - & 0.09 & 0.34 & NA & NA & - & 20 \\
\hline 55 & III & 0 & het & WT & 10.8 & + & 1.94 & 0.97 & NA & NA & - & 10 \\
\hline 57 & III & 0 & WT & WT & 1.3 & - & 0.04 & 0.52 & NA & NA & - & 30 \\
\hline 59 & III & 0 & WT & WT & 22.4 & - & 0.04 & 0.66 & $9.5 \pm 0.1$ & $1.9 \pm 0.2$ & - & NA \\
\hline 61 & III & 0 & WT & WT & 33.5 & - & 0.03 & 0.49 & $11.5 \pm 1.2$ & NA & - & 40 \\
\hline 62 & III & 0 & WT & WT & 0.9 & - & 0 & 0.86 & NA & NA & - & 50 \\
\hline 63 & III & 0 & WT & WT & 1.4 & - & 0.01 & 0.43 & $8 \pm 0.1$ & $1 \pm 0.2$ & NA & 30 \\
\hline 65 & III & 0 & WT & WT & 59.7 & - & 0.04 & 1.18 & $11.7 \pm 2.7$ & NA & - & NA \\
\hline 66 & III & 0 & WT & WT & 48.9 & - & 0 & 0.58 & $6.7 \pm 2$ & $1.8 \pm 0.4$ & + & 30 \\
\hline 69 & III & 0 & WT & WT & 33.7 & - & 0 & 0.76 & $19.9 \pm 1.1$ & $1.7 \pm 0.6$ & - & NA \\
\hline 70 & III & 0 & WT & WT & 4.7 & - & 0.05 & 1.05 & $11.1 \pm 2.7$ & $4.1 \pm 0.8$ & - & NA \\
\hline 71 & III & 1 & WT & WT & 2.1 & - & 0.04 & 1 & $8.8 \pm 0.6$ & $1.3 \pm 0.1$ & - & NA \\
\hline 72 & III & 0 & WT & WT & 1.7 & - & 0.04 & 0.67 & $12.7 \pm 1.6$ & NA & - & 50 \\
\hline 73 & III & 0 & WT & WT & 1.3 & - & 0.04 & 0.87 & $9.7 \pm 3$ & $1.5 \pm 0.3$ & - & NA \\
\hline 74 & III & 0 & WT & WT & 0.9 & - & 0.03 & 0.97 & NA & $0.8 \pm 0.1$ & - & NA \\
\hline
\end{tabular}




\begin{tabular}{|c|c|c|c|c|c|c|c|c|c|c|c|c|}
\hline 76 & III & 0 & $\begin{array}{c}\mathrm{R} 132 \mathrm{H} \\
\text { het }\end{array}$ & WT & 17.6 & + & 14.28 & 1.15 & $<0.01$ & $1.2 \pm 0.2$ & + & NA \\
\hline 77 & III & 0 & WT & WT & 5.1 & - & 0.13 & 0.87 & $9.8 \pm 1$ & NA & - & 30 \\
\hline 78 & III & 1 & $\begin{array}{c}\text { R132H } \\
\text { het }\end{array}$ & WT & 50.9 & - & 0.13 & 0.79 & $15.2 \pm 4.4$ & $2 \pm 0.5$ & - & 40 \\
\hline 80 & III & 0 & WT & WT & 29.2 & - & 0.03 & 0.57 & $5.4 \pm 0.1$ & $0.5 \pm 0.1$ & + & NA \\
\hline 82 & III & 0 & WT & WT & 1.4 & - & 0.08 & 0.74 & NA & $4.8 \pm 0.7$ & + & 30 \\
\hline 83 & III & 0 & WT & WT & 4.4 & - & 0.05 & 0.88 & $23.2 \pm 6.8$ & $2.1 \pm 0.2$ & - & 60 \\
\hline 84 & III & 0 & WT & WT & 12.6 & - & 0.11 & 0.78 & $7.9 \pm 0.9$ & $3.3 \pm 0.6$ & + & NA \\
\hline 85 & III & 0 & WT & WT & 2.0 & - & 0.02 & 0.93 & $6.5 \pm 1.5$ & $1.9 \pm 0.5$ & - & NA \\
\hline 86 & III & 1 & $\begin{array}{c}\mathrm{R} 132 \mathrm{H} \\
\text { het }\end{array}$ & WT & 48.2 & - & 0.01 & 1 & $8.8 \pm 1.1$ & $2.7 \pm 0.3$ & NA & 30 \\
\hline 87 & III & 0 & WT & WT & 1.8 & - & 0.01 & 0.62 & $7.9 \pm 0.1$ & $2.4 \pm 0.2$ & - & 40 \\
\hline 88 & III & 0 & WT & WT & 37.0 & - & 0.07 & 0.7 & $6.2 \pm 5$ & $3.1 \pm 0.1$ & - & NA \\
\hline 89 & III & 0 & WT & WT & 34.9 & - & 0.01 & 1.16 & $8.7 \pm 2.5$ & $0.9 \pm 0.1$ & - & 25 \\
\hline 90 & III & 0 & WT & WT & 48.1 & - & 0 & 0.7 & $12.2 \pm 1.2$ & $2.5 \pm 0.3$ & - & 30 \\
\hline 91 & III & 0 & WT & WT & 20.8 & - & 0.02 & 0.77 & $5.4 \pm 1.2$ & $1.6 \pm 0.1$ & - & 40 \\
\hline 92 & III & 0 & WT & WT & 0.8 & - & 0.09 & 0.85 & $33.6 \pm 4.1$ & $2.9 \pm 0.5$ & - & 60 \\
\hline
\end{tabular}

(a) $1 \mathrm{p} / 19 \mathrm{q}$ codel. (codeletion $1 \mathrm{p} / 19 \mathrm{q}$ ): 1 , present; 0 , absent.

(b) MGMT mean methylation: mean methylation of $\mathrm{CpG} \# 74$ to 78 expressed in \% methylation of each CpG sites determined using pyrosequencing.

(c) The intensity of the $\mathrm{C}$-circle signal was quantified with respect to the intensity of the $\mathrm{P}^{32}$ signal on the dot blot from which the background intensity of the nylon membrane had been subtracted. The mean value of the C-circle signal for HeLa cells, 0.23 , was taken as a threshold for defining C-circle-positive tumors although two tumors, \#17 and \#41, with a score of 0.27 and 0.25 , respectively, were not considered positive in this C-circle assay, because these values were too close to the HeLa cells signal. The mean value for 10 samples of U2OS cells in three different experiments was found to be 21.0.

(d) p53: mutated (+) or wild-type (-). 


\section{SUPPLEMENTARY DATA}

\section{Supplementary methods}

\section{DNA sequencing for IDH1/2 mutational analysis and methylation status of MGMT promoter}

Genomic DNA was isolated from frozen tissues using the QIAamp DNA Mini Kit (Qiagen) and stored at $-80^{\circ} \mathrm{C}$. $I D H 1$ and $I D H 2$ genotyping was performed by EpigenDx (Worcester, MA, US) using pyrosequencing. MGMT exon 1 methylation status was determined by EpigenDx (Worcester, MA, US) using the reproducible and sensitive bisulfite based-pyrosequencing strategy. Data were provided as $\%$ of methylation observed on the 5 CpG sites already described [1] as diagnostic CpG sites (cf PyroMark Q96 CpG MGMT kit from Qiagen: +34 from ATG (+65 from TSS), +39 from ATG (+70 from TSS), +42 from ATG (+73 from TSS), +46 from ATG (+77 from TSS) and +48 from ATG (+79 from TSS). The methylation status was defined according to the average methylation value of the $5 \mathrm{CpG}$ sites of methylation, namely unmethylated when mean methylation was $<8 \%$ and methylated when mean methylation was $>8 \%[2]$.

\section{Analysis of 1p/19q codeletion}

The analysis of 1p/19q codeletion was performed using the Vysis 1p36/1q25 and 19q13/19p13 FISH Probe Kit (4N6020, Abbott), according to manufacturer's instructions. 1p/19q status was lacking for some patients. In these cases, internexin neuronal intermediate filament protein alpha (INA) expression was reported to be a surrogate marker of $1 \mathrm{p} / 19 \mathrm{q}$ codeletion [3, 4]. For certain patients, in addition to FISH or INA, Copy Number Variation (CNV) measurements were performed afterwards, using the Cytoscan HD Affymetrix system. Among all patients analyzed using both CNV analysis and INA or FISH, patient \#71 was the only one for whom there was a disagreement between the two methods. Immunohistochemical analyses were carried out on paraffin sections using antibodies directed against INA (see below).

\section{Immunostaining}

Immunohistochemistry for Ki-67 (clone MIB-1, dilution 1:150, Code no. M7240, Dako, Glostrup, Denmark), p53 (clone DO7, dilution 1:1000, Cat.\#CM042C, Biocare Medical, Concord, CA, US), alpha-internexin (clone 2E3, dilution 1:300, Cat\#MAB5224, Millipore Corporation, Billerica, MA, US) and ATRX (dilution 1:500, Cat\#HPA001906, Sigma-Aldrich, Saint-Quentin Fallavier, France) were performed using the Benchmark Ventana system (Roche) as per the manufacturer's recommendations. Sections were semiquantitatively scored by light microscopy and percentage of stained tumor cells and staining intensity was evaluated. For p53, only 
tumors with more than $70 \%$ of tumor cells demonstrating high intensity of p53 staining were considered as p53 mutated. For alpha-internexin, positive tumors were the ones with cytoplasmic staining observed in more than $10 \%$ of tumoral cells. For ATRX, a lack of nuclear positivity on tumoral cells was associated with an ATRX mutation.

\section{Measurements of ALT-specific C-circles}

The C-circle assay, which detects partially single-stranded telomeric (CCCTAA)n DNA circles (C-circles) amplified by the Phi29 polymerase in the absence of dCTP, was performed as described previously [5]. Genomic DNA was digested with $4 \mathrm{U} / \mu \mathrm{g}$ HinfI and $R s a \mathrm{I}$ restriction enzymes and $25 \mathrm{ng} / \mu \mathrm{g}$ of Dnase-free RNase). Ten $\mu \mathrm{l}$ of each sample (10 ng) was combined with $10 \mu \mathrm{l} 0.2 \mathrm{mg} / \mathrm{ml} \mathrm{BSA,} 0.1 \%$ Tween, $1 \mathrm{mM}$ each dATP, dGTP and dTTP, $1 \times$ Phi29 Buffer and 7.5 U Phi29 DNA polymerase (Thermo Scientific, Fermentas) and incubated at $30^{\circ} \mathrm{C}$ for $8 \mathrm{~h}$, then at $65^{\circ} \mathrm{C}$ for $20 \mathrm{~min}$. For quantification, the reaction products were diluted to $60 \mu \mathrm{l}$ with $2 \mathrm{x}$ SSC and dot-blotted onto a 2x SSC-soaked Hybond $\mathrm{N}^{+}$nylon membrane (GE Heathcare). DNA was UV-cross-linked onto the membrane, which was then hybridized at $37^{\circ} \mathrm{C}$ with end-labeled ${ }^{32} \mathrm{P}-(\mathrm{CCCTAA})_{3}$ and PerfectHyb Plus hybridization buffer (Sigma). Results were analyzed using a GE Storm phosphorimager and the ImageQuant software.

\section{Detection of ALT-associated promyelocytic leukemia nuclear bodies (APBs) at the telomeres}

APBs detection was conducted according to protocols previously described $[6,7]$. Slides containing 8 - $\mu \mathrm{m}$-thick sections from paraffin-embedded tumor samples were dewaxed and rehydrated by two washes in xylene for 5 min each, two washes in $100 \%$ ethanol for 5 min each, one wash in $70 \%$ ethanol for 5 min and finally immersed in distilled water to rinse off ethanol. Antigen retrieval was then performed by incubating the slides for 20 min at $100^{\circ} \mathrm{C}$ in a pressure cooker containing sodium citrate buffer at $\mathrm{pH}$ 6.0. The slides were then cooled and rinsed in PBS. Cells were then permeabilized by incubation with $0.5 \%$ Triton X-100 in PBS for 15 min. After three washes in $0.5 \% \mathrm{BSA}$, in PBS, they were blocked by incubation for $30 \mathrm{~min}$ in $7.5 \% \mathrm{BSA}, 7.5 \%$ FBS and 0.1\% Triton X-100 in PBS. Cells were incubated at room temperature for $1 \mathrm{~h}$ with an antibody against PML (1:50, Santa Cruz) and then with FITC-conjugated secondary antibody, at room temperature, for $1 \mathrm{~h}$. Sections were then cross-linked with $4 \%$ formaldehyde and dehydrated. Telomere fluorescence in situ hybridization was done by denaturing slides together with the telomeric cyanin-3-conjugated (CCCTAA) $)_{3}$ peptide nucleic acid (PNA) probe (Eurogentec) in $70 \%$ formamide, $0.25 \%$ blocking reagent (Roche), $10 \mathrm{mM}$ Tris $\mathrm{pH} 7.2$, for $5 \mathrm{~min}$ 
at $75^{\circ} \mathrm{C}$ and hybridizing overnight at $37^{\circ} \mathrm{C}$. Slides were washed in $70 \%$ formamide, $10 \mathrm{mM}$ Tris $\mathrm{pH} 7.2,0,1 \%$ BSA, counterstained with DAPI and mounted in Vectashield medium (Vector Laboratories). Images were captured on a Nikon epifluorescence microscope using NIS-Element D 3.1 image analysis software.

\section{Measurement of telomeric DNA transcription (TERRA)}

Two micrograms of tumor sample RNA were reverse transcribed using the Revertaid first strand cDNA synthesis kit from Thermo Scientific-Fermentas, with gene specific primers (see below) and random hexamers as primers for $G A P D H$. cDNAs were diluted to a final concentration of $10 \mathrm{ng} / \mu \mathrm{l}$ in sterile $\mathrm{H}_{2} \mathrm{O}$ and amplified using a Bio-Rad Mini-Opticon instrument. Amplification was performed in $20 \mu \mathrm{l}$ of reaction mix, containing $5 \mu 1$ of diluted cDNA and $15 \mu \mathrm{l}$ Mesa Green qPCR Mastermix Plus (Eurogentec), together with forward and reverse primers. Cycling conditions were $10 \mathrm{~min}$ at $95^{\circ} \mathrm{C}$, followed by 45 cycles of $15 \mathrm{~s}$ at $95^{\circ} \mathrm{C}$ (denaturation) plus 1 min at $60^{\circ} \mathrm{C}$ (annealing/extension). At the end of the PCR run, melting curves of the amplified products were used to determine the specificity of the amplification reaction. Quantitative data of the samples were obtained using the BioRad CFX Manager software. All cDNA samples were assayed in triplicates. We chose the GAPDH as the endogenous normalizer because its expression was constant. The threshold cycle number for TERRA was normalized to $G A P D H$. TERRA expression was determined by the $\triangle \triangle \mathrm{Ct}$ method. The primers used for PCR amplification of total TERRA transcription measurement were as previously described [8], namely Tel1b: 5'-

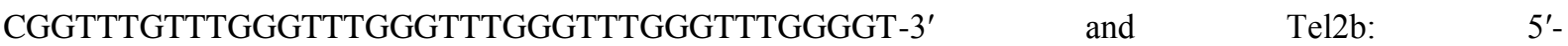
GGCTTGCCTTACCCTTACCCTTACCCTTACCCTTACCCT-3'. The presented data represent the average \pm standard error for three replicates.

\section{Cell lines and cell culturing}

The following human cell lines were purchased from the American Type Culture Collection (ATCC) and the German Collection of Microorganisms and Cell Cultures (DSMZ) and were used to measure telomere length of cell populations, as described below. These were 8-MG-BA, a GBM cell line (DSMZ \#ACC 432), Hs-683, an oligodendroglioma cell line (ATCC \#HTB-138J3), 42-MG-BA, a GBM cell line (DSMZ \#ACC 431), U-87 MG, a GBM astrocytoma cell line (ATCC \#HTB-14), T98G, a GBM cell line (ATCC \#CRL-1690), HeLa, an adenocarcinoma cell line (ATCC \#CCL-2) and U2OS, an osteosarcoma, ALT-positive, cell line. Cells were cultivated in Minimum Eagle's medium (MEM) supplemented with $10 \%$ fetal bovine serum (FBS, PAA) in the 
presence of 5\% CO2 in a 90\%-humidified incubator or in Dulbecco's modified Eagle's medium (DMEM) supplemented with $10 \%$ FBS in the presence of $5 \% \mathrm{CO} 2$.

Telomere length measurement of human cancer cell lines by telomere restriction fragment (TRF) analysis To analyze telomere length by TRF [9], genomic DNAs were prepared from the cultured cell lines listed above, digested with RsaI and HinfI and separated in a $0.9 \%$ agarose gel (in TBE) run in TBE buffer overnight and, after denaturation, transferred and hybridized with a (TTAGGG) ${ }_{3}{ }^{32} \mathrm{P}$-labeled telomeric probe. Following digestion of genomic DNA, telomere tracts of wild-type cells appear as a broad band which represents the average length of most chromosomes. Results were analyzed using a GE Storm phosphorimager and the ImageGauge software.

\section{Supplementary results}

\section{Telomeric DNA content}

Measurement of telomere length by Southern blot analysis, also referred to as TRF (Telomere Restriction Fragment) analysis [9] is currently considered as the gold standard for telomere length measurement [10]. However, when dealing with clinical samples for which the amounts of tumor DNA are often limited, TRF analysis is difficult because it requires a minimum of around $5 \mu \mathrm{g}$ of DNA. In the current study, we had approximately $30 \mathrm{ng}$ of tumor DNA available for each sample, once all the other analyses had been performed. To circumvent this problem, we quantified telomeric DNA (TTAGGG repeats) with respect to an internal control, namely the amount of Alu repeats, referred to as the Telo/Alu dot blot method (Figure 2A, Supplementary Table 1). A statistical study (see below) was conducted on the raw data obtained as explained above. However, in an attempt to determine an approximate absolute value for telomere length, we simultaneously measured telomere length by TRF and quantified telomeric DNA by the Telo/Alu dot blot method in cultured cells from six different human cell lines (Figure 2B). This strategy allowed us to confirm that the Telo/Alu dot blot signals were indeed proportional to telomere length measured by TRF. In addition, this could potentially be useful if approximate absolute values of telomere length, in kilobases, were needed for future glioma characterization.

No statistically significant difference in telomeric DNA content was found in relation with IDHI/2 mutational status (Table 1). On the other hand, a significant positive association was found between long telomeres and the presence of C-circles ( $\mathrm{p}=0.03,0.7$ [0.54 - 0.87] versus 0.83 [0.70 - 1], Table 2). For instance, 
tumor \#30 exhibited a $42.18 \mathrm{C}$-circle score and a 1.77 Telo/Alu ratio, the highest among all tumors measured (Supplementary Table 1). Finally, statistical analyses showed no correlation between telomeric DNA content/telomere length and survival $(\mathrm{HR}=1.16,[0.41-3.31], \mathrm{p}=0.78)$.

\section{Telomeric DNA transcripts (TERRA)}

Telomeric DNA is transcribed into the non coding RNAs called TERRA [11]. In mammalian cells, TERRA molecules play an important role in regulating telomere structural maintenance and heterochromatin formation [12]. We therefore set out to measure TERRA levels in the 34 out of 63 gliomas for which enough material was available (Supplementary Table 1). A correlation between increased TERRA expression and better survival was found in multivariate analysis $(\mathrm{p}=0.07$,$) . On the other hand, no statistically different value in TERRA levels$ was found between the IDH mutated and IDH WT gliomas ( $\mathrm{p}=0.68$, Table 1). Likewise, no statistically significant difference in TERRA expression was found between C-circle negative and positive tumors (Table 2).

\section{References}

1 Karayan-Tapon L,_ Quillien V, Guilhot J et al (2010). Prognostic value of O6-methylguanine-DNA methyltransferase status in glioblastoma patients, assessed by five different methods. J Neuro-Oncol 97:311-22. 2 Quillien V, Lavenu A, Karayan-Tapon L et al (2012). Comparative assessment of 5 methods (methylationspecific polymerase chain reaction, MethyLight, pyrosequencing, methylation-sensitive high-resolution melting, and immunohistochemistry) to analyze O6-methylguanine-DNA-methyltranferase in a series of 100 glioblastoma patients. Cancer 118:4201-11.

3 Ducray F, Crinière E, Idbaih A et al (2009). Alpha-internexin expression identifies 1p19q codeleted gliomas. Neurology 72:156-61.

4 Ducray F, Mokhtari K, Crinière E et al (2011). Diagnostic and prognostic value of alpha internexin expression in a series of 409 gliomas. Eur J Cancer 47:802-8.

5 Henson JD, Cao Y, Huschtscha LI et al (2009). DNA C-circles are specific and quantifiable markers of alternative-lengthening-of-telomeres activity. Nat Biotechnol 27:1181-6.

6 Henson JD, Hannay JA, SmcCarthy SW et al. (2005). A robust assay for Alternative Lengthening of Telomeres in tumors shows the significance of Alternative Lengthening of Telomeres in sarcomas and astrocytomas. Clin Cancer Res 11:217-25. 
7 Yeager T, Neumann A, Englezou A et al (1999). Telomerase-negative immortalized human cells contain a novel type of promyelocytic leukemia (PML) body. Cancer Res 59: 4175-9.

8 Sampl S, Pramhas S, Stern C et al (2012). Expression of telomeres in astrocytoma WHO grade 2 t0 4: TERRA level correlates with telomere length, telomerase activity, and advanced clinical grade. Transl Oncol 5:56-65.

9 Broccoli D, Godley LA, Donehower LA et al (1996). Telomerase activation in mouse mammary tumours: lack of telomere shortening and evidence for regulation of telomerase with RNA cell proliferation. Mol Cell Biol $16: 3765-72$.

10 Aubert G, Hills M, Lansdorp PM (2012). Telomere length measurement - Caveats and a critical assessment of the available technologies and tools. Mut Res 730:59-67.

11 Azzalin CM, Reichenbach P, Khoriauli L et al (2007). Telomeric repeat containing RNA and RNA surveillance factors at mammalian chromosome ends. Science 318:798-801.

12 Azzalin CM, Lingner J (2014). Telomere functions grounding on TERRA firma. Trends Cell Biol 25:29-36. 